\title{
Characterization of Focal Breast Lesions by Means of Elastography
}

\section{Charakterisierung von Herdläsionen der Brustdrüse mittels Elastografie}

Authors

Affiliations

\author{
T. Fischer ${ }^{1}$, I. Sack ${ }^{2}$, A. Thomas $^{3}$
}

1 Institute of Radiology and Ultrasound Research Laboratory, Charité - University Berlin

2 Institute of Radiology, Charité - University Berlin

${ }^{3}$ Department of Gynecology and Obstetrics and Ultrasound Research Laboratory, Charité - University Berlin

\author{
Key words \\ - elastography \\ - strain ratio \\ - breast lesion \\ - ultrasound \\ - MRI
}

eingereicht 2.9 .2012

akzeptiert 18.5.2013

\section{Bibliography}

Dol http://dx.doi.org/

10.1055/s-0033-1335939

Published online: 25.7.2013

Fortschr Röntgenstr 2013; 185 :

816-823 @ Georg Thieme

Verlag KG Stuttgart · New York . ISSN 1438-9029

\section{Correspondence}

PD Dr. Anke Thomas

Klinik für Gynäkologie und Geburtshilfe,

Universitätsmedizin Berlin, Charité

Charitéplatz 1

10117 Berlin

Tel.: ++49/30/450564172

Fax: ++49/30/450527975

anke.thomas@charite.de

\section{Abstract \\ $\nabla$}

Purpose: The modern method of sonoelastography of the breast is used for differentiating focal lesions. This review gives an overview of the different techniques available and discusses their roles in the routine clinical setting. Materials and Methods: The presented techniques include compression or vibration elastography as well as shear wave elastography. Descriptions of the methods are supplemented by a discussion of the clinical role of each technique based on the most recent literature. We discuss by outlining two recent experimental approaches - MRI and tomosynthesis elastography.

Results: Currently available data suggest that elastography is an important supplementary tool for the differentiation of breast tumors under routine clinical conditions. The specificity improves with the immediate availability of additional diagnostic information using real-time techniques and/or the calculation of strain ratios (SR). Elastography is especially helpful in women with involuted breasts for differentiating BI-RADS-US 3 and 4 lesions and for evaluating very small cancers without the typical imaging features of malignancy. Here, elastography techniques are highly specific, while the sensitivity decreases compared to B-mode ultrasound. SR calculation is especially helpful in women who have a high risk of breast cancer and high pretest likelihood.

Conclusion: B-mode ultrasound is still the first-line method for the initial evaluation of the breast. If suspicious findings are detected, elastography with or without SR calculation is the most crucial supplementary tool.
Key Points:

- Improved specificity for elastography and SR calculation.

- Significant benefits for high-risk collective (BRCA mutation).

Citation Format:

- Fischer T, Sack I, Thomas A Characterization of Focal Breast Lesions by Means of Elastography. Fortschr Röntgenstr 2013; 185: 812 823

\section{Zusammenfassung}

$\nabla$

Ziel: Die moderne Methode der sonografischen Elastografie der Brustdrüse dient der Differenzierung von Herdbefunden. Diese Übersichtsarbeit beschreibt die verschiedenen Methoden und Ansätze sowie deren Nutzen im klinischen Alltag. Material und Methoden: Sowohl die Kompressions- oder Vibrationselastografie als auch die Scherwellenelastografie werden methodisch beschrieben und ihre Wertigkeit im klinischen Alltag anhand der aktuellen Literatur belegt. Ebenfalls werden MR- und Tomosynthese-Elastografie als experimenteller Ansatz diskutiert.

Ergebnisse: Bei der derzeitigen Datenlage kann die Elastografie als wichtiges Zusatzkriterium zur Differenzierung von Mammatumoren in der Routine Einzug halten. Es zeigt sich eine Verbesserung der Spezifität bei sofortigem Informationsgewinn durch den Einsatz der Real-Time-Methode und/ oder der Strain-Ratio-Kalkulation (SR). Anwendungsgebiete sind in der Trennung der Kategorie BI-RADS-US 3 und 4, insbesondere bei Brustdrüseninvolution sowie bei sehr kleinen Karzinomen ohne typische Malignitätskriterien zu sehen, wo hoch spezifische Ergebnisse erzielt werden, wenngleich die Sensitivität im Vergleich zum B-Bild abfällt. Insbesondere im Subkollektiv mit hohem Brustkrebsrisiko sollte die hohe Vor-Testwahr- 
scheinlichkeit der SR-Kalkulation Eingang in das diagnostische Prozedere finden.

Schlussfolgerung: Suchmethode der Wahl bleibt die B-Bildsonografie, erst bei auffälligem Befund stellt die Elastografie mit und ohne SR das entscheidende Zusatzkriterium dar.

\section{Introduction}

$\nabla$

Since the beginning of the 1990s, the term elastography has been used in ultrasound to refer to a number of different methods for visualizing tissue strain [1-3]. An important property of tissue is intrinsic elasticity which can change due to pathophysiological processes such as aging, inflammation, or tumorous processes. In this case elasticity is the ratio of the required stress (pressure) to the achieved relative change in length (strain, distortion). Therefore, it describes how much pressure must be applied to a tissue to cause it to deform elastically as a function of its intrinsic elasticity modulus (Young's modulus) $[4,5]$. The benefit of using tissue elasticity as additional information has been able to be shown for years in clinical studies for numerous organ systems. In addition to elasticity studies of organs such as the parotid gland [6], thyroid gland [7, 8], liver [9, 10], prostate gland [11], and cervix [12], special effort has been made to characterize the formation of focal breast lesions [13-15]. Verification of a lack of strain of a focal finding in breast sonography is an indicative status criterion which improves the diagnostic reliability of sonography in particular. In addition to the increase in specificity [1317], better differentiation was able to be achieved between benign and malignant focal findings, particularly between BI-RADS-US 3 and BI-RADS-US 4. Therefore, the number of false-positive findings in breast diagnostics was able to be reduced by using elastography as an additional criterion [14]. It is conceivable that the number of unnecessary biopsies will be able to be reduced in the future in this way. Additional validation of the method using unselected screening populations is necessary but has been insufficient to date [18-20].

Strain elastography, compression elastography, vibration elastography, and shear wave elastography are presented in the following ( $\bullet$ Fig. 1). The status of the individual meth-

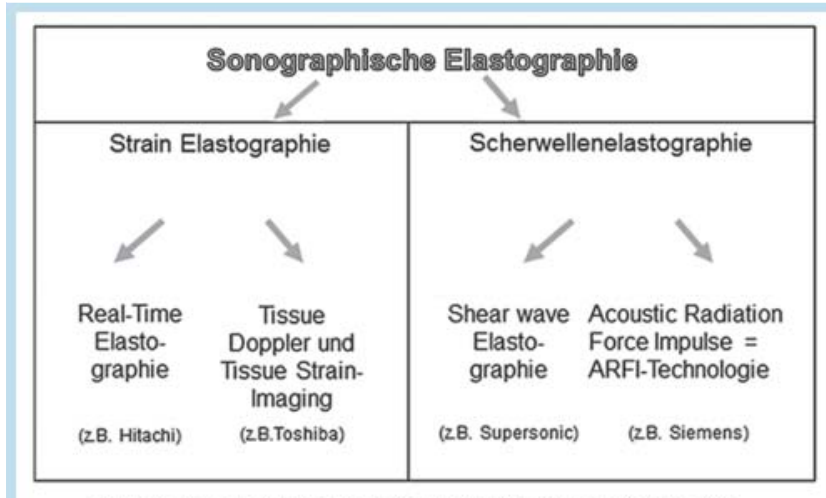

Quantifizierung: SR=Strain Ratio=FLR=Fat-Lesion Ratio, E-Ratio

Fig. 1 Sonographic elastography methods. ods in a clinical context is explained on the basis of current publications with the clinical benefit being in the forefront.

\section{Sonographic elastography}

\section{Strain elastography (compression elastography)}

In strain elastography (also referred to as compression or vibration elastography), the tissue is subjected to tension stress via uniform, repetitively vibrating pressure introduced by an external stimulus, the ultrasound wave, or pulsation of large vessels, and the resulting compression is measured. It must be noted that the induced compression is a volume-retaining distortion since the examined soft tissues are always virtually incompressible. However, this assumption can only be conditionally transferred to human tissue. Since the actual displacement deformation of the tissue (also referred to as shear strain) is often called compression or strain in the literature on elastography, we will adhere to these terms in the following.

Today's simplified measurement options were preceded by numerous in vitro studies at the start of the $1980 \mathrm{~s}$. The tissue stimulus was studied in complex lab experiments to determine whether the vibration is exerted on the tissue in a static, dynamic, or pulsed manner [21-24]. Experiments regarding the type of measurement were also conducted to determine whether measurements should be performed in the strain or compression phase and whether the strain rate or the pressure has to be used as the measurement basis [4]. This resulted in the first in vivo experiments [25, 26] which resulted in real-time elastography [5]. The elastographic tissue properties are determined by a relative change in length as a function of the applied pressure. The elasticity modulus $\mathrm{E}$ which is measured in $\mathrm{N} / \mathrm{m}^{2}$ or $\mathrm{kPa}$ describes the relationship between distortion and external force effect in the material. The higher $\mathrm{E}$ is, the lower the resulting distortion. Consequently, tissue with a high $\mathrm{E}$ is harder than tissue with a low E [27].

A principle problem of this technique is the variable pressure distribution at different tissue depths so that a certain selective interpretation of the findings (examiner bias) must be taken into consideration in the evaluation.

In real-time elastography, the ultrasound probe compresses the tissue externally and causes it to move. The tissue elasticity initially cannot be derived directly from the reflected raw ultrasound data. The extent of the tissue displacement before and after compression is determined in a first step. This can then be used to reconstruct a three-dimensional distortion field so that the elasticity modulus can be calculated using the known pressure of the probe [5]. The technical further development of the autocorrelation method in which the raw ultrasound data is used to calculate the total distortion field within the probe width made it possible to calculate tissue strain data on all three spatial planes. Echo frequency patterns along an ultrasound beam are recorded with respect to time. In addition, multiple parallel ultrasound beams can be observed at the same time. This has the advantage that a lateral displacement of hard tissue occurring under pressure can be compensated since the transmission time of the ultrasound waves is also recorded. The tissue compression results in a relative distortion of the ultrasound $\mathrm{A}$ lines that can be compensated via correlation 

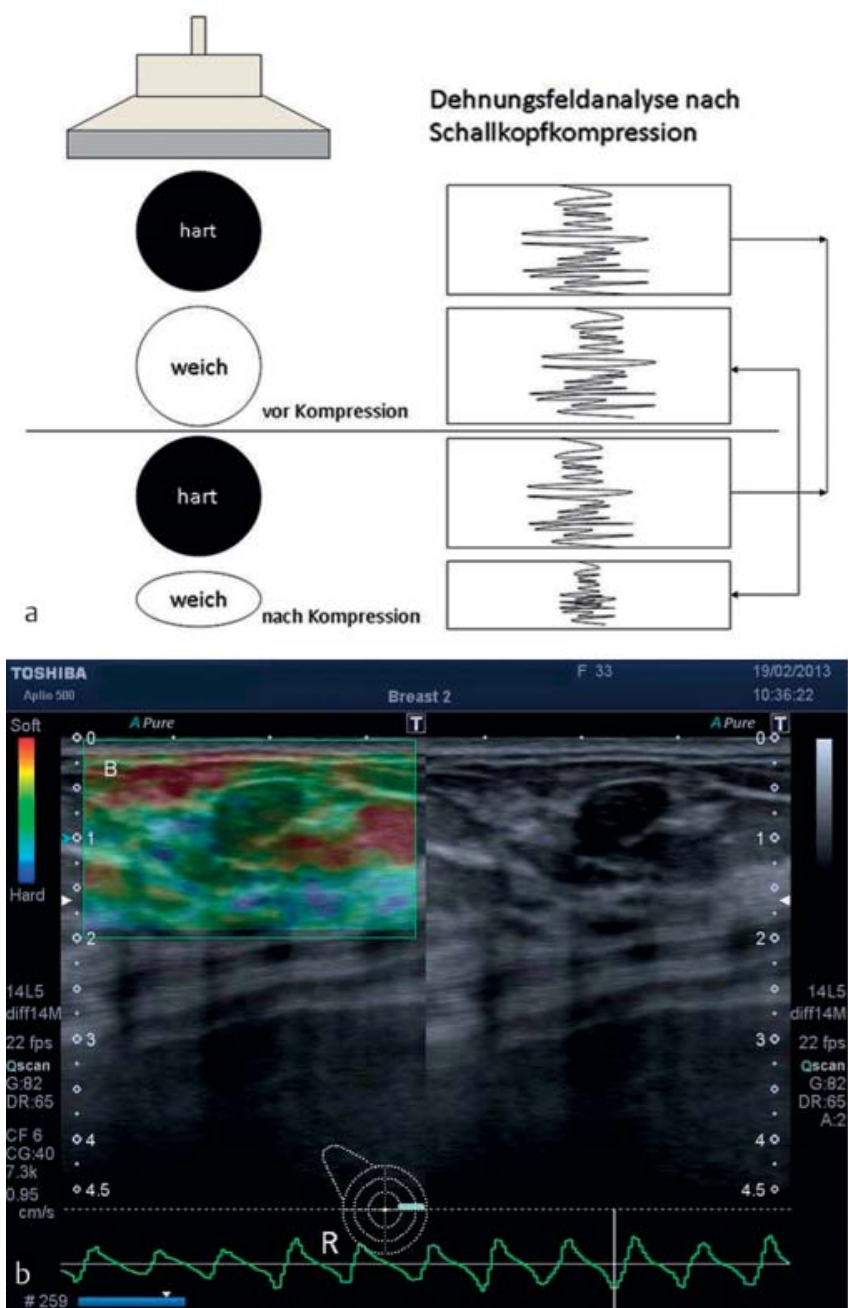

Fig. 2 a Diagram of real-time elastography. The external tissue compression by the ultrasound probe causes the tissue to move. A significant displacement of the amplitude is characteristic for elastic tissue, while a constant distance of the ultrasonic oscillation patterns indicates the presence of hard tissue. $\mathbf{b}$ The B-mode image on the right side shows a hypoechoic tumor with smooth borders (BI-RADS-US 2). The elastogram on the left side shows a focal finding in green, i. e., the tumor is medium hard. The tumor is

of the displaced oscillation pattern. Significant displacement of the amplitude is characteristic for elastic tissue, while a constant distance of the ultrasonic oscillation pattern indicates the presence of hard tissue ( $\bullet$ Fig. 2a). A color scale with a $256 \times 256$ matrix is used to subjectively estimate tissue strain. The colors of the blue color spectrum have been defined for low intrinsic elasticity in numerous publications and the colors of the green to red spectrum have been defined as average to high elasticity ( $\bullet$ Fig. $\mathbf{2 b - c}$ ). However, these color scales can be defined by the user and reversed in today's modern US systems even though standardization independent of a commercial company policy would be desirable. Initial studies were able to show simple application and good interobserver validity as well as improved differentiation of focal lesions in breast sonography [17]. Numerous additional studies were able to confirm these results [13-16, $28-30]$. It was also shown that elastography significantly improves status evaluation and the detection of focal findings in the case of lipomatous in-
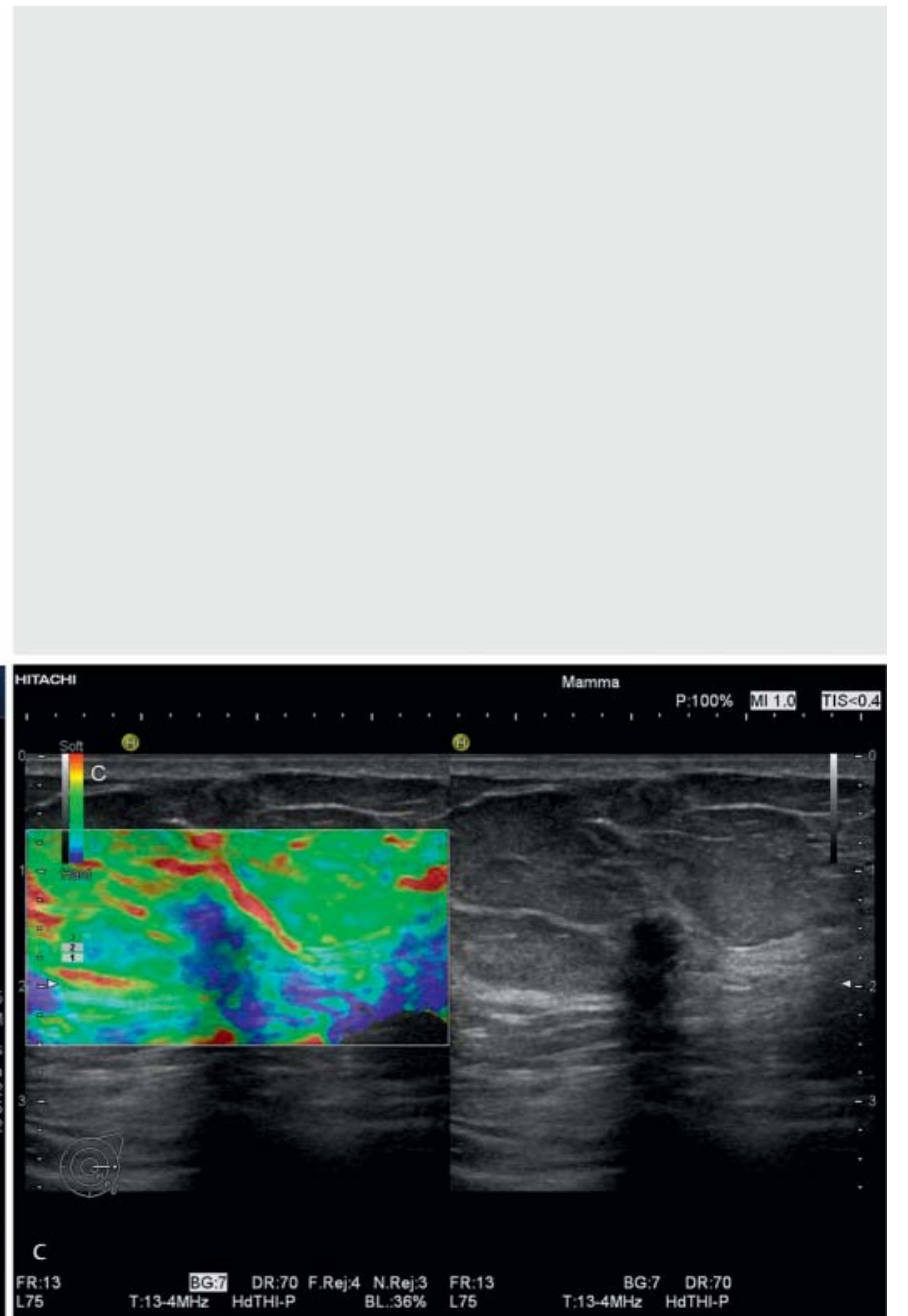

a fibroadenoma. The uniform compression and decompression exerted by the examiner with the linear probe can be tracked in real time on the screen. c Image of a 6-mm focal finding in the left breast in dual mode. The right half of the image shows a focal finding with spiculation and a halo effect (BI-RADS-US IV), while the elastogram on the left half shows no intrinsic elasticity. The blue color corresponds to the invasive ductal carcinoma verified with punch biopsy.

volution of the mammary gland [17]. Since the use of the Bmode in the case of involution of the breast parenchyma is limited [31,32], a specificity increase in the case of mammary gland involution from $69 \%$ to $80 \%$ as a result of the use of real-time elastography was able to be shown in the study by Thomas et al. [17]. These data were able to be confirmed in a multicenter study including 779 women [14]. The reason for the increased specificity could be the improved visualization of the focus and its borders to the surrounding fatty tissue since elastography is able to show the minor differences in echogenicity between tumor and fat and additional malignancy criteria, such as spiculation, can be detected with elastography.

The first image descriptions used the score system developed by $\mathrm{E}$. Ueno, which classifies the strain in a focal finding according to 5 categories [16]. The so-called Tsukuba score can be integrated in the established BI-RADS-US criteria of the ACR catalog for better comparability. Tsukuba 
scores 1 and 2 correspond to BIRADS-US 2, while scores 3 5 are equivalent to BI-RADS-US 3 - 5 (๑ Tab. 1 ).

Although the known studies have shown good interobserver validity, compression elastography has been reported to have a certain amount of subjectivity in the execution of the examination and the interpretation of the focal findings but this plays a secondary role in the clinical routine in our opinion.

\section{Strain ratio calculation}

In the further development for improved standardization of the method, a semiquantitative evaluation, the so-called
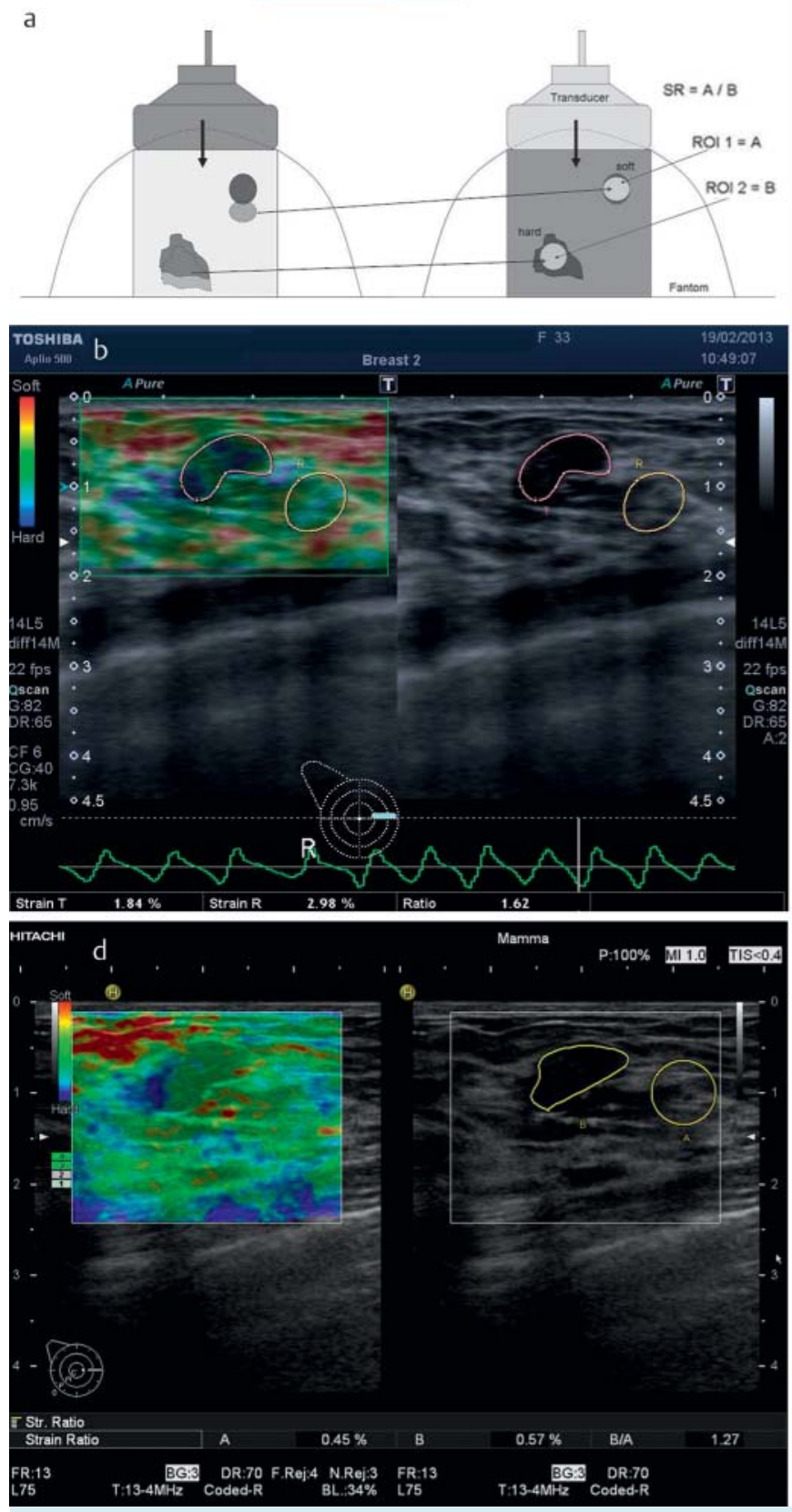

Fig. 3 a Schematic representation of the SR calculation after compression of the tissue by the probe. The ratio of the fatty tissue strain a to the tumor strain $\mathbf{b}$ can then be calculated offline. $\mathbf{b}$ The strain ratio of 1.62 is significantly less than the cut-off value of 2.27 [33]. This also confirms the histologically verified fibroadenoma from $\bullet \mathbf{F i g}$. $\mathbf{2 b}$. c The ROI selected in the decompression phase yields a ratio between fatty tissue (yellow marking) and fat-lesion ratio $=$ strain ratio $(\mathrm{FLR}=\mathrm{SR})$ was introduced. This is defined as the ratio of the strain in the fatty tissue to the

Tab. 1 Comparison of the image analysis categories using BI-RADS-US criteria according to ACR and the Tsukuba score.

\begin{tabular}{|lll|}
\hline & BI-RADS-US criteria & Tsukuba score \\
\hline 1 & normal finding & strain in the entire area \\
\hline 2 & definitely benign & strain in the focal lesion \\
\hline 3 & probably benign & strain in the periphery of the tumor \\
\hline 4 & suspicious for malignancy & no strain in the focal lesion \\
\hline 5 & highly suspicious & no strain around the focal lesion \\
\hline
\end{tabular}
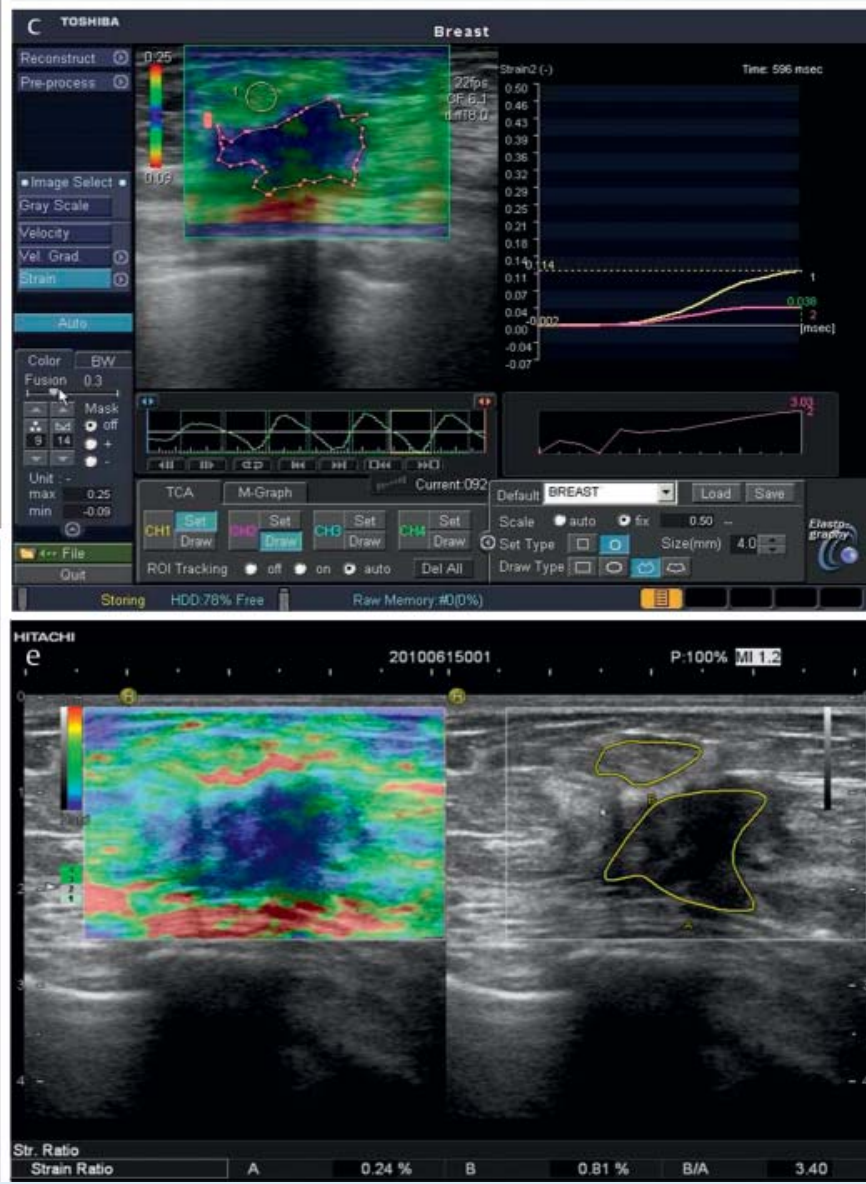

tumor (pink marking) of 3.03. The SR value indicates a malignancy. Histology acquired via punch biopsy of an invasive ductal carcinoma. $\mathbf{d}$ A strain ratio of 1.27 also confirms the benign finding of the known fibroadenoma. The value is also below the cut-off value of 2.455 [15]. $\mathbf{b}$ The SR value of 3.4 correlates to the histological finding of a malignancy. Image of the focal finding from $\mathbf{c}$ with various high-end systems which can be seen in $\mathbf{b}-\mathbf{e}$. 
strain of the breast tumor ( $\bullet$ Fig. 3a). Since fatty tissue can be assumed to be a sufficiently good interindividual reference standard with a constant Young's modulus even between different women, the measurement is considered reproducible. A region of interest (ROI) in the entire breast tumor as well as in the surrounding fatty tissue is used to calculate a value to be compared individually and intraindividually [15]. It was able to be shown in the current studies that both improved status evaluation and the use of a cutoff value make it possible to differentiate between benign and malignant focal findings ( $\bullet$ Fig. 3b-e). In a European patient collective, this value was 2.455 using Hitachi equipment [15] and 2.27 using Toshiba equipment [33]. Since the cut-off value can differ depending on the country, e.g. a cut-off value of 3.05 was calculated in China [34], there are no standardized limit values. This could be due to the different population-dependent breast tissue densities. This SR value can be used for simple and reproducible status evaluation of a previously detected focal finding. If the measured data are below the cut-off value, the finding is primarily benign ( $\bullet$ Fig. 3b-d). However, if the cut-off value is exceeded, the finding is typically malignant ( $\bullet$ Fig.3c-e) and requires histological verification. The value should be measured in the decompression phase, since this is less dependent on the introduced pressure ( $\bullet$ Fig. 3 b-c). This provides added reliability for inexperienced examiners in particular and builds the foundation for future applications, i. e., a sonographic CAD system [35]. The use of the SR for differentiating between relapse and scar was not productive. Since scar tissue after operation and radiation has minimal intrinsic elasticity, the SR values are in the malignant range. To rule out relapse, MRI or histological verification via US-guided punch biopsy continues to be the standard procedure [36]. A further advancement in compression elastography technology is the visualization of compression and decompression curves which show the examiner the less pressure-dependent decompression phase and thus help to standardize the examination. The examiner can see whether continuous and uniform pressure is being exerted

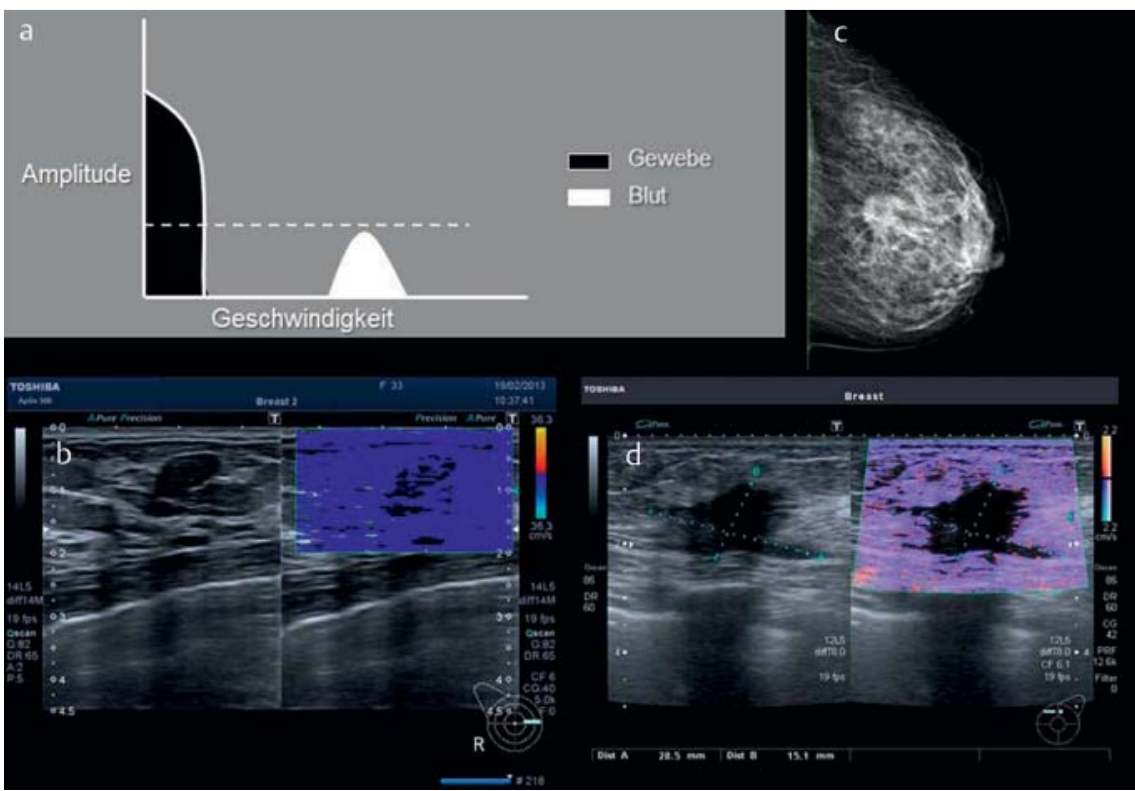

on the tissue (compression and decompression) without having to leave the image plane ( $\bullet$ Fig. $3 b, c)$.

\section{Tissue Doppler Imaging Method}

The tissue Doppler imaging method is a special form of strain elastography that is pressure-independent. In this case the shear strain due to the tissue displacement caused by the ultrasound wave is examined. It is also possible to perform a real-time analysis using the tissue Doppler imaging (TDI) method. The tissue displacement caused by the TDI procedure is very slow but has a very high amplitude compared to the fast signals and low amplitude of the erythrocytes that serve as reflectors in the classic Doppler method ( $\bullet$ Fig. 4a). In dual mode the tissue distortion is displayed as color-coded superimposition of the B-mode image with the known Doppler colors red and blue. The ratio from the maximum cross-sectional area of the focus formation in the B-mode image (ROI) can be put in proportion to the color pixel-free area of the TDI image [35]. Malignancies have a characteristic color pixel-free area while benign foci are typically significantly smaller on the TDI image and are filled with color pixels ( $\bullet$ Fig. 4b-d). As a result, benign and malignant focal findings can be differentiated with significance $(\mathrm{p}<0.001)$. This method is simple to use, provides immediate information, and can be theoretically implemented on any device. In addition, the strain can be quantified offline using the acquired data. To derive this tissue strain imaging (TSI) from the raw data, a standardized pressure could initially only be calculated using a phantom measurement. This was put in proportion to the maximum distortion factor in the selected ROI in the focal finding and then used to calculate the distortion score. An increase in specificity was also seen here due to the use of this offline analysis [37]. This method is also based on the analysis of frequency shifts. The effect of the pressure from the probe is used with the analysis of the raw ultrasound data to calculate a compression or decompression curve. The recording of the entire strain curve over time is advantageous because it is material-specific. Automatic angle correction takes into account the tissue strain in all spatial directions for precise re-
Fig. 4 a Basic physical principle of TDI. $\mathbf{b}$ In the case of good tissue displacement, the benign focal finding is almost completely filled with color pixels of the Doppler signal. The tissue is thus elastic. c Digital mammography (MLO image) of the left breast with verification of a BI-RADS $\vee$ focal finding. d The same focal finding in TDI shows an area that is completely free of color pixels. The spiculation is particularly visible. The area quotient between Bmode and TDI is 1 . The strong suspicion of breast cancer is confirmed by punch biopsy. 
presentation of the total strain [38]. A distortion ratio was subsequently able to be calculated in the further development. The study at two German centers showed good agreement in the analysis (AUC 0.907) with significant differentiation between malignant and benign focal findings (33) performed in the form of a second reading.

\section{Shear wave elastography}

Shear wave elastography (SWE) and so-called transient elastography (TE) use another basic physical principle. A special probe is necessary. In addition to the "classic" ultrasound wave, it generates a low-frequency shear wave in the frequency range of $50 \mathrm{~Hz}$. The elasticity modulus can be determined from the propagation rate of the shear wave or transverse wave ( $\bullet$ Fig. 5 ).

This technique has become important in recent years particularly for determining the degree of fibrosis in the liver $[39,40]$. Current publications discuss the degree of fibrosis of kidney transplantations. Stock et al. [41] described a relationship between elastographic values determined via the ARFI (Acoustic Radiation Force Impulse) technique and the histologically verified degree of fibrosis. The ARFI technique is similar to TE but the shear wave is generated via focused ultrasound pulses and a single-region velocity measurement is used.

SWE is based on high-energy ultrasound push pulses that are emitted vertical to the surface and generate multiple acoustic centers deep in the tissue from which the slow transverse shear waves emanate radially and form a wave front ( $\bullet$ Fig. 5a). The propagation of the shear wave front is recorded with very fast B-mode ultrasound imaging and the propagation rate is calculated. This correlates with the elasticity modulus ( $\bullet$ Fig. 5b). In contrast to the ARFI technique, multiregion velocity measurements are performed in this case. To date, only a few studies have been applied to clinical evaluation for the differentiation of focal breast lesions. As a result, Evans et al. [42] and Berg et al. [43] were able to determine that the use of shear wave elastography increases specificity and also improves the evaluation of the status of breast findings ( $\bullet$ Fig. 6 ). The main advantage of the method is the good interobserver validity and pressure independence so that it can be assumed that the method will find wider application. Quantifiable results can also be reproducibly represented.

In 2012 Sadigh et al. conducted a first large metaanalysis regarding the use of ultrasound elastography (USE) for the differentiation of focal breast lesions compared to B-mode imaging (USB) and the combination of the two methods (dependent and independent) [44, 45]. It was shown on the basis of 5,511 breast lesions that elastography alone increases the specificity from $70 \%$ (USB) to $88 \%$ (USE) but came at the price of a partially reduced sensitivity (96\% vs. $79 \%$ ), while the number of correct classifications did not differ significantly. Rather it was able to be shown that the combination of methods (USB + USE) particularly in a screening collective with a low risk of breast cancer has a

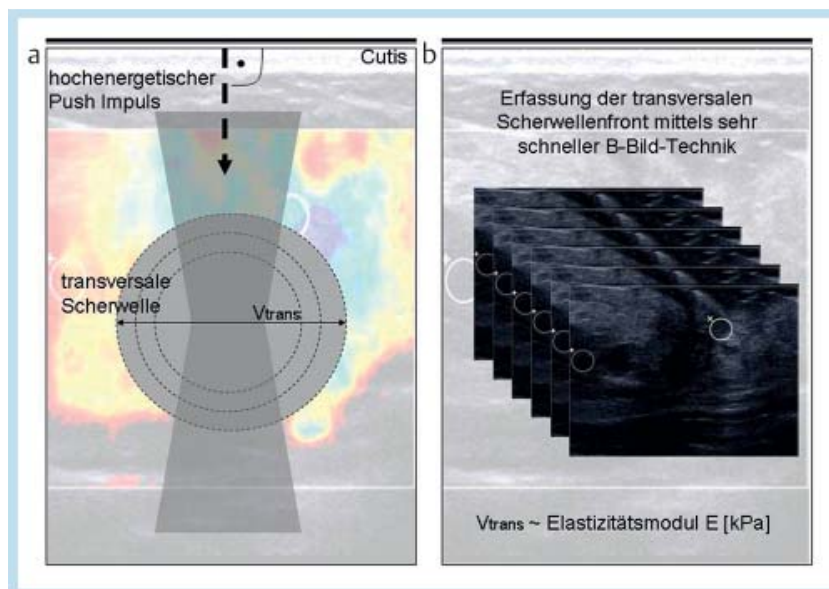

Fig. 5 Shear wave elastography (SWE). a SWE is based on high-energy ultrasound push pulses that are emitted vertical to the surface and generate multiple acoustic centers deep in the tissue from which the slow transverse shear waves emanate radially and form a wave front. $\mathbf{b}$ The propagation of the shear wave front is recorded with very fast ultrasound B-mode imaging and the propagation rate is calculated. This correlates with the elasticity modulus.

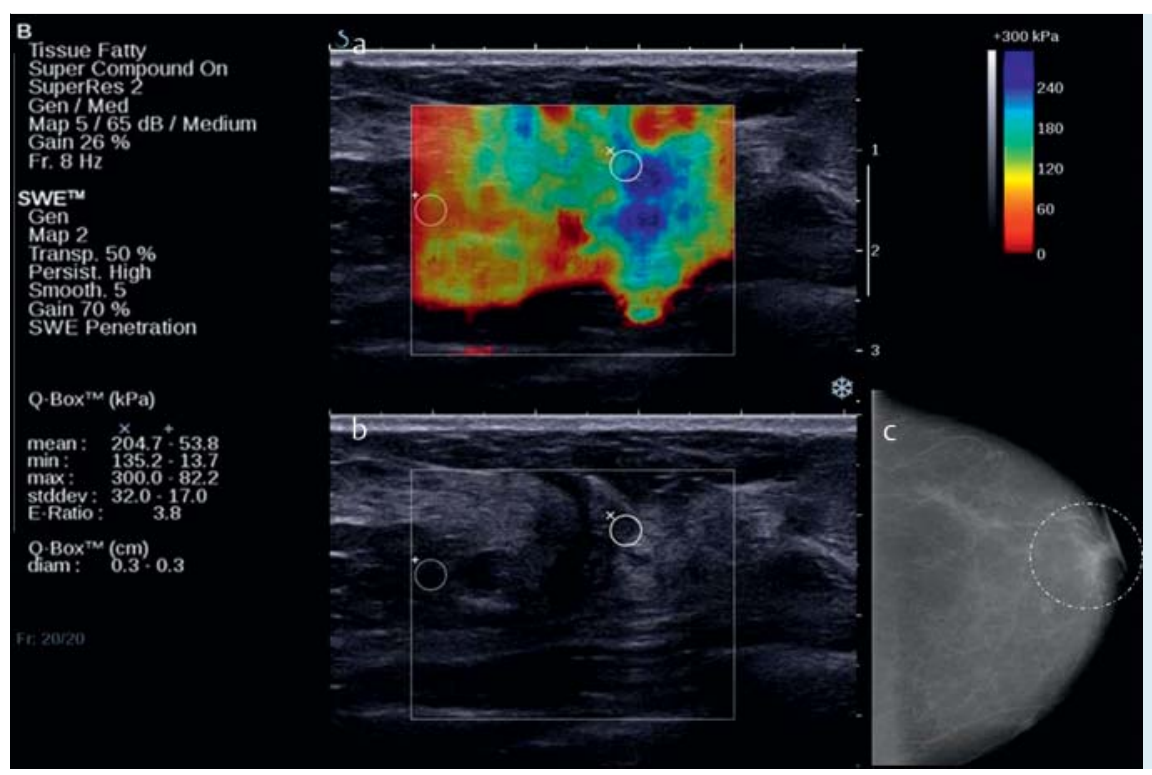

Fig. 6 In this case, the suspicious focal finding does not expand (blue colors, 204KPa in the ROI) and has an E-ratio of 3.8 a. The B-mode image shows a structural abnormality for this histologically verified invasive lobular carcinoma $\mathbf{b}$. Mammography showed discrete thickening (white ring) centrally on the CC plane without a correlate on the 2nd plane $\mathbf{c}$. 
significant advantage (28\% increase in specificity compared to USB, AUC $97 \%$ vs. $92 \%$ ). The authors concluded that it would be possible to reduce the number of biopsies in this subcollective with a low carcinoma prevalence by using elastography. The diagnostic cascade would indicate elastography in the case of a positive B-mode finding but primary use of the method does not seem expedient. Punch biopsy or follow-up could then be planned within 6 months.

In 2012 Sadigh et al. were able to demonstrate a pooled sensitivity of $88 \%$ and a specificity of $83 \%$ in 2,087 focal findings by including the strain ratio in the metaanalysis. Higher pre-test probabilities compared to the subjective scoring of USE were seen in the risk collective. Consequently, a possible approach would be subjective scoring of USE for a screening population with a low risk in the case of an abnormal B-mode image (BI-RADS-US category III-IV). However, the test with the highest correct classification rate should be used in a high-risk collective, in this case SR calculation which has a higher sensitivity than the subjective findings of USE.

\section{Alternative elastographic methods}

Additional methods such as the use of shear wave elastography in MRI (MR elastography, MRE [46]) promise a further increase in the diagnostic quality of imaging methods for the characterization of breast lesions [47-49]. The inherent limitations of MRE such as long examination times and reduced spatial resolution can be compensated with modern single-shot imaging techniques and multi-frequency vibrations [49-51]. On the whole it can be expected that MRE of the breast will be used in the future as a short supplementary examination in addition to the clinically indicated standard MRI of the breast $[52,53]$. A further promising method for mechanical characterization of breast tissue is tomosynthesis elastography. With the tomosynthesis method, the tissue layers are imaged before and after static distortion and are converted to distortion maps via image registration routines [54].

Regardless of the medical imaging modality, elastography is a valid means of determining pathological differences in the degree of breast tissue crosslinking. Mechanical stimulation can be used to generate diagnostic information in the image contrast that would otherwise only be able to be obtained invasively.

\section{Summary \\ $\nabla$}

Given the current data, elastography can be applied to the clinical routine as an important additional criterion for the differentiation of breast tumors. Using real-time methods and/or strain ration calculation improves specificity and provides immediate information. Elastography is highly specific in the case of fatty involuted breasts as well as for the differentiation between BIRADS-US 3 and 4 and in the case of very small carcinomas without typical malignancy criteria even if the sensitivity is lower than for B-mode imaging. It was shown in individual cases that focal findings appearing benign in B-mode sonography can be categorized as malignant in the elastogram in the case of an anamnestically greater risk of breast cancer or verification of a BRCA mutation. The high pre-test probability of the SR calculation should be applied to the diagnostic procedure particularly in the case of this subcollective with a high risk of breast cancer. B-mode sonography remains the search method of choice. Elas-
Tab. 2 Possible limitations of sonographic elastography.

Limitations of elastography
- posterior position of a focal lesion
- fibrosis surrounding a hard focus formation
- fatty tissue surrounding a soft lesion
- drop-out artifact with significant acoustic shadowing for shear wave
elastography
- dCIS can present an elasticity modulus like that of fat under weak pre-
compression
- the introduced pressure can only be conditionally standardized for
strain elastography

tography with and without SR only provides a helpful additional diagnostic criterion for characterizing focal findings in the case of a pathological finding. It must be determined on the basis of larger collectives whether inexperienced examiners can profit from this in the future. Since the time and financial expenditure for the method is minimal, a cost-benefit analysis would yield positive results for elastography. A particularly simple method is TDI which can in principle be made available on any system without additional costs. Invasive lobular carcinomas in particular can be diagnosed with this method. Methods requiring complex equipment, such as MR elastography and tomosynthesis elastography, represent interesting experimental approaches but currently do not yet provide the spatial resolution of sonographic elastography and are consequently not ready for routine use.

Finally, several important limitations of sonographic elastography must be mentioned again. When minor elasticity differences between the surroundings and a lesion are able to be measured or the basic assumption malignant = hard, benign $=$ soft is not applicable for the tissue properties of the lesion (e. g. in the case of a scar), the elastography method is not productive. The most important limitations are listed in $\bullet$ Table 2.

The use of sonographic elastography can be recommended for differentiating BI-RADS-US categories 3 and 4 and in high-risk collectives (SR calculation) based on the publications cited here.

\section{Acknowledgement}

$\nabla$

This manuscript is dedicated to Professor Bernd Hamm for his 60th birthday.

\section{References}

1 Céspedes I, Ophir J, Ponnekanti H et al. Elastography: elasticity imaging using ultrasound with application to muscle and breast in vivo. Ultrason Imaging 1993; 15: 73-88

2 Garra BS, Cespedes EI, Ophir J et al. Elastography of breast lesions: initial clinical results. Radiology 1997; 202: 79-86

3 Krouskop TA, Wheeler TM, Kallel F et al. Elastic moduli of breast and prostate tissues under compression. Ultrason Imaging 1998; 20 : $260-274$

4 Konofagou E, Ophir J. A new elastographic method for estimation and imaging of lateral displacements, lateral strains, corrected axial strains and Poisson's ratios in tissues. Ultrasound Med Biol 1998; 24: 1183-1199

5 Frey $H$. Realtime-Elastographie. Ein neues sonografisches Verfahren für die Darstellung der Gewebeelastizität. Radiologe 2003; 10: 850

6 Klintworth N, Mantsopoulos K, Zenk J et al. Sonoelastography of parotis gland tumours: initial experience and identification of characteristics patterns. Eur Radiol 2012; 22: 947-956 
7 Rubaltelli L, Corradin S, Dorigo A et al. Differential diagnosis of benign and malignant thyroid nodules at elastosonography. Ultraschall in Med 2009; 30: 175-179

8 Hong Y, Liu X, Li Z et al. Real-time ultrasound elastography in the differential diagnosis in benign and malignant thyroid nodules. J Ultrasound Med 2009; 28: 861 - 867

9 Kanamoto $M$, Shimada M, Ikegami $T$ et al. Real time elastography for non invasive diagnosis in liver fibrosis. J Hepatobiliary Pancreat Surg 2009; 16: 463-467

10 Friedrich-Rust M, NierhoffJ, Lupsor $M$ et al. Performance of acoustic radiation force impulse imaging for the staging of liver fibrosis: a pooled meta-analysis. J of Viral Hepatitis 2012; 19: e212 - e219

11 Aigner F, Pallwein L, Junker D et al. Value of real-time elastography targeted biopsy for prostate cancer detection in men with prostate specific antigen $1.25 \mathrm{ng} / \mathrm{ml}$ or greater and $4.00 \mathrm{ng} / \mathrm{ml}$ or less. J Urol 2010; 184: $913-917$

12 Thomas A, Kümmel S, Gemeinhardt 0 et al. Real-time sonoelastography of the cervix: tissue elasticity of the normal and abnormal cervix. Acad Radiol 2007; 14: 193-200

13 Thomas A, Kümmel S, Fritzsche F et al. Real-time sonoelastography performed in addition to B-mode ultrasound and mammography: improved differentiation of breast lesions? Acad Radiol 2006; 13: 1496-1504

14 Wojcinski S, Farrokh A, Weber S et al. Multicenter study of ultrasound real-time tissue elastography in 779 cases for the assessment of breast lesions: improved diagnostic performance by combining the $\mathrm{BI}-$ RADS $^{\circledR}$-US classification system with sonoelastography. Ultraschall in Med 2010; 31: 484-491

15 Thomas A, Degenhardt F, Farrokh A et al. Significant differentiation of focal breast lesions: calculation of strain ratio in breast sonoelastography. Acad Radiol 2010; 17: 558-563

16 Itoh A, Ueno E, Tohno E et al. Breast disease: clinical application of US elastography for diagnosis. Radiology 2006; 239: 341-350

17 Thomas A, Fischer T, Ohlinger $R$ et al. Real-time elastography - an advanced method of ultrasound: First results in 108 patients with breast lesions. Ultrasound Obstet Gynecol 2006; 28: 335 - 340

18 American College of Radiology (ACR). Breast Imaging and Reporting Data Systems (BI-RADS $\left.{ }^{\circledR}\right)$. Breast Imaging Atlas. Reston, VA: American College of Radiology; 2003

19 Schmachtenberg C, Engelken F, Fischer T et al. Intraoperative Specimen Radiography in Patients with Nonpalpable Malignant Breast Lesions. Fortschr Röntgenstr 2012; 184: 635-642

20 Waldmann A, Adrich S, Eisemann $N$ et al. Struktur- und Prozessqualität in der qualitätsgesicherten Mammadiagnostik in Schleswig-Holstein. Fortschr Röntgenstr 2012; 184: 113-121

21 Ophir J, Céspedes I, Ponneanti $H$ et al. Elastography: a quantitative method for imaging the elasticity of biological tissue. Ultrason Imaging 1991; 13: $111-114$

22 Catheline S, Wu F, Fink M. A solution to diffraction biases in sonoelasticity: the acoustic impulse technique. J Acoust Soc Am 1999; 105: $2941-2950$

23 Parker KJ, Lerner RM. Sonoelasticity of organs: shear waves ring a bell. J Acoust Soc Am 1999; 105: 2941 - 2950

24 Sandrin L, Tanter M, Catheline S et al. Shear modulus imaging with 2-D transient elastography. IEEE Trans Ultrason Ferroelectr Freq Control 2002; 49: 426-435

25 Hiltawsky KM, Krüger M, Starke C et al. Freehand ultrasound elastography of breast lesions: clinical results. Ultrasound Med Biol 2001; 27: $1461-1469$

26 Bercoff J, Chaffai S, Tanter $M$ et al. In vivo breast tumor detection using transient elastography. Ultrasound Med Biol 2003; 10: 1387-1396

27 Lorenzen J, Sinkus R, Adam G. Elastographie: Quantitative Bildgebung der elastischen Gewebeeigenschaften. Fortschr Röntgenstr 2003; 175: $623-630$

28 Kolb TM, Lichy J, Newhouse JH. Comparison of the performance of screening mammography, physical examination, and breast US and evaluation of factors that influence them: An analysis of 27825 patient evaluations. Radiology 2002; 225: 165-175

29 Schaefer FK, Heer I, Schaefer PJ et al. Breast ultrasound elastography results of 193 breast lesions in a prospective study with histopathologic correlation. Eur J Radiol 2011; 77: 450-456

30 Lee JH, Kim SH, Kang BJ et al. Role and clinical usefulness of elastography in small breast masses. Acad Radiol 2011; 18: 74-80

31 Tan SM, Teh HS, Mancer JF et al. Improving B mode ultrasound evaluation of breast lesions with real-time ultrasound elastography - A clinical approach. Breast 2008; 17: 252-257
32 Zhi H, Ou B, Luo B et al. Comparison of ultrasound elastography, mammography, and sonography in the diagnosis of solid breast lesions. J Ultrasound Med 2007; 26: 807-815

33 Fischer T, Peisker U, Fiedor $S$ et al. Significant differentiation of focal breast lesions: raw data-based calculation of strain ratio. Ultraschall in Med 2012; 33: 372 - 379

34 Zhi H, Xiao XY, Yang HY et al. Ultrasonic elastography in breast cancer diagnosis: stain ratio vs. 5-point scale. Acad Radiol 2010; 17: $1227-$ 1233

35 Moon WK, Chang RF, Chen CJ et al. Solid breast masses: classification with computer-aided analysis of continuous US images obtained with probe compression. Radiology 2005; 236: 458 - 464

36 Quinn EM, Coveney AP, Redmond HP. Use of magnetic resonance imaging in detection of breast cancer recurrence: a systematic review. Ann Surg Oncol 2012; 19: 3035-3041

37 Thomas A, Warm M, Diekmann F et al. Tissue doppler and strain imaging for evaluating tissue elasticity of breast lesions. Acad Radiol 2007; 14: $522-529$

38 Beier S. Standardisierte Dehnungsfeldanalyse am Brustphantom und Einführung des Gewebedopplerverfahrens zur Differenzierung mammasonografischer Herdbefunde [Internet]. Verfügbar unter: http:/ www.diss.fu-berlin.de/diss/receive/FUDISS_thesis_000000020335

39 Friedrich-Rust M, Ong M-F, Martens $S$ et al. Performance of transient elastography for the staging of liver fibrosis: a meta-analysis. Gastroenterology 2008; 134: 960-974

40 Friedrich-Rust M, Schwarz A, Ong M et al. Real-time tissue elastography versus FibroScan for noninvasive assessment of liver fibrosis in chronic liver disease. Ultraschall in Med 2009; 30: 478-484

41 Stock KF, Klein BS, Vo CongMT et al. ARFI-based tissue elasticity quantification in comparison to histology for the diagnosis of renal transplant fibrosis. Clin Hemorheol Microcirc 2010; 46: 139-148

42 Evans A, Whelehan P, Thomson K et al. Differentiating benign from malignant solid breast masses: value of shear wave elastography according to lesion stiffness combined with greyscale ultrasound according to BI-RADS classification. Br J Cancer 2012; 107: 224-229

43 Berg WA, Cosgrove DO, Doré CJ et al. Shear-wave elastography improves the specificity of breast US: the BE1 multinational study of 939 masses. Radiology 2012; 262: 435-449

44 Sadigh G, Carlos RC, Neal CH et al. Ultrasonographic differentiation of malignant from benign breast lesions: a meta-analytic comparison of elasticity and BIRADS scoring. Breast Cancer Res Treat 2012; 133: 23 - 35

45 Sadigh G, Carlos RC, Neal CH et al. Accuracy of quantitative ultrasound elastography for differentiation of malignant and benign breast abnormalities: a meta-analysis. Breast Cancer Res Treat 2012; 134: 923-931

46 Muthupillai R, Lomas DJ, Rossman P et al. Magnetic resonance elastography by direct visualization of propagating acoustic strain waves Science 1995; 269: 1854-1857

47 Sinkus R, Siegmann K, Xydeas T et al. MR elastography of breast lesions: understanding the solid/liquid duality can improve the specificity of contrast-enhanced MR mammography. Magn Reson Med 2007; 58 : $1135-1144$

48 Plewes DB, Bishop J, Samani A et al. Visualization and quantification of breast cancer biomechanical properties with magnetic resonance elastography. Phys Med Biol 2000; 45: 1591 - 1610

49 Van Houten EE, Doyley MM, Kennedy FE et al. Initial in vivo experience with steady-state subzone-based MR elastography of the human breast. J Magn Reson Imaging 2003; 17: $72-85$

50 Klatt D, Hamhaber $U$, Asbach $P$ et al. Noninvasive assessment of the rheological behavior of human organs using multifrequency MR elastography: a study of brain and liver viscoelasticity. Phys Med Biol 2007; 52: $7281-7294$

51 Papazoglou S, Hirsch S, Braun J et al. Multifrequency inversion in magnetic resonance elastography. Phys Med Biol 2012; 57: 2329-2346

52 Hausmann D, Kern C, Schroder MT et al. Ganzkörper-MRT in der präoperativen Diagnostik des Mammakarzinoms - ein Vergleich mit den Stagingmethoden in der S 3-Leitlinie. Fortschr Röntgenstr 2011; 183: $1130-1137$

53 Muller-Schimpfle MP, Heindel W, Kettritz $U$ et al. Konsensustreffen der Kursleiter in der Mammadiagnostik am 7.5.20111 in Frankfurt am Main - Magnet-Resonanz-Tomografie der Mamma. Fortschr Röntgenstr 2012; 184: 919-924

54 Engelken FJ, Sack I, Klatt D et al. Evaluation of tomosynthesis elastography in a breast-mimicking phantom. Eur J Radiol 2012; 81: 2169 2173 